\title{
Anaemia and its association with month and blood phenotype in blood donors in Fako division, Cameroon
}

Tebit Emmanuel Kwenti ${ }^{1,2,3^{*}}$ and Tayong Dizzle Bita Kwenti ${ }^{3}$

\begin{abstract}
Background: Anaemia is one of the main factors in the deferral (disqualification) of blood donors following haematological screening. There is paucity of data on the prevalence of anaemia in blood donors in Sub-Saharan Africa. This study was undertaken to determine the prevalence of anaemia and its association with month and blood phenotype in blood donors in Fako division of Cameroon.

Methods: Blood donors were recruited between the 1st of January and 31st of December 2014, and their haemoglobin concentration $(\mathrm{Hb})$ was determined using a haemoglobinometer. Anaemia was considered as $\mathrm{Hb}<12 \mathrm{~g} / \mathrm{dl}$ for females and $\mathrm{Hb}<13 \mathrm{~g} / \mathrm{dl}$ for males. The $\mathrm{ABO}$ and Rhesus blood groups were determined using standard techniques with monoclonal antibodies and the Coombs' test. The Pearson's chi-square, Pearson's correlation, student $T$ test, ANOVA, univariate and multivariable logistic regression analyses adjusting for gender and age as categorical variable were all performed as part of the statistical analysis.

Results: A total of 1896 blood donors predominantly males (91.35\%) took part in the study. The mean age of the donors was $32 \pm 7.81$ years. On average, donors had donated blood $5.07 \pm 3.54$ times in their lifetime. The prevalence of anaemia observed in this study was 31.44\% (95\% Cl: 29.35-33.58). The prevalence of anaemia was higher in females $(p \leq 0.0001)$ and in participants of age 20 years and below $(p=0.001)$. A marginal association was observed between prevalence of anaemia and season $(p=0.051)$. Furthermore, a significant association was observed between prevalence of anaemia and the blood group $A B(p=0.001)$. The risk of developing anaemia was higher in females compared to males $(\mathrm{OR}=2.7, p<0.0001)$. The mean $\mathrm{Hb}$ observed in this study was $13.42 \pm 1.65$; the mean $\mathrm{Hb}$ was not observed to be associated with the month or season adjusting for age and gender.
\end{abstract}

Conclusion: This study revealed a high prevalence of anaemia which translates to a high rate of donor deferral as a result of anaemia in the study area. The prevalence of anaemia was observed to be associated with the blood phenotype and the month, but not the season (dry or rainy). Further studies will be needed to ascertain the aetiology and associated factors for anaemia in blood donors in the study area.

Keywords: Anaemia, Blood donors, Prevalence, Association, Blood phenotype, Season, Fako Division, Cameroon

\footnotetext{
* Correspondence: kwentitebit@yahoo.com

${ }^{1}$ Regional Hospital Buea, P.O. Box 32, Buea, South West Region, Cameroon

${ }^{2}$ Department of Medical laboratory Sciences, Faculty of Health Sciences,

University of Buea, P.O. Box 63, Buea, Cameroon

Full list of author information is available at the end of the article
} 


\section{Background}

Anaemia is a condition where there is a decrease in the amount of red blood cells or less than the normal quantity of haemoglobin in the blood. It is the most common disorder of the blood and it symbolizes both poor nutrition and poor health [1]. The causes of anaemia are multifactorial and may result from blood loss, decreased red blood cell production or increased red blood cell breakdown [2]. Anaemia is a global public health problem affecting nearly a quarter of the world's population [3]. Although its effect is felt in both developing and developed countries, developing countries are the most affected [4]. The management of anaemia commonly involves the use of iron pills, intravenous iron, and erythropoiesis-stimulating medications or by blood transfusion on a case-by-case basis.

The impact of anaemia on maternal and child health is well recognised. Severe anaemia has been linked to increased risk of maternal and child mortality $[1,5,6]$. Anaemia has also been linked to impaired psychological and physical development, behaviour, and work performance of the population [7]. In Cameroon, like most countries in Sub-Saharan Africa, the prevalence of anaemia is very high. In 2011, the prevalence was estimated at $63.3 \%$ in children and $49.5 \%$ in pregnant women [8]. Malnutrition is one of the main culprit for anaemia in Africa [9]. In addition to malnutrition, there are also infectious causes of anaemia in Cameroon including malaria and intestinal parasitic infections [10-12].

The impact of anaemia on a country's blood banking services has received relatively little attention. Anaemia is one of the main reasons for deferral (disqualification) of potential blood donors [13]. In countries where the prevalence of anaemia is high, this will have a profound effect on the blood stock, eventually compromising the quality of health care. This is not very unusual in developing countries like Cameroon where shortages of blood and blood products are frequent due to the high demand driven by the high rate of anaemia.

The prevalence of anaemia doesn't seem to be constant all year round. In one study, Bondevik et al. [14] had observed a clear seasonal variation of the risk of anaemia in pregnant Nepali women, associated with rainfall and temperature. An earlier study by Palva and Salokannel [15] had also reported a seasonal variation in megaloblastic anaemia. Studies on the seasonal variation of anaemia among blood donor are not readily available.

In Cameroon, data on the prevalence of anaemia among blood donors is lacking in the scientific literature. It was against this drawback that we conducted this study to determine the prevalence of anaemia among blood donors in the Fako Division of Cameroon. The association between anaemia and blood phenotype, and between anaemia and month were also determined. This will generate baseline data which hopefully will be useful in the planning and implementation of blood transfusion services in the country.

\section{Methods \\ Study design and duration}

This was a cross-sectional study which started on the 1st of January and concluded on the 31st of December 2014. The study participants were donors who came to donate blood in the Regional Hospital of Buea during the study period.

\section{Study area}

The study was performed in Fako Division $\left(4^{\circ} 10^{\prime} 00^{\prime \prime} \mathrm{N}, 9^{\circ}\right.$ $10^{\prime} 00$ "E) of the South West Region of Cameroon. The department covers an area of $2093 \mathrm{~km}^{2}$ with an elevation of $2707 \mathrm{~m}$ above sea level. Fako Division has an estimated population of 534,854 [16]. The major towns in Fako Division include Buea, Idenau, Limbe (Divisional headquarter), Muyuka and Tiko. The climate of Fako division is generally hot and dry with the exception of Buea where the climate tends to be humid because of its location at the foot of Mount Cameroon. Fako division has two seasons, the rainy and the dry seasons. The rainy season is usually between April and September, and the dry season is between October and March.

\section{Study population}

Blood donors (males or females) in the Regional Hospital of Buea were approached to take part in the study. Participants were to be between the ages 17 and 52 years and of weight $\geq 50 \mathrm{~kg}$. All participants were expected to provide a signed informed consent which was duly explained to them in English, French or the local broken English language. Excluded from the study were individuals who did not meet the criteria for blood donation (unfit) such as donors on any medication, women who were breastfeeding or those on menstruation, and donors who had donated blood within 3 months prior to the study.

Participants were consecutively recruited into the study as they came to donate. Participants were enrolled just once and a single blood sample was collected from the participants.

\section{Measurement of blood haemoglobin concentration $(\mathrm{Hb})$} Participants' $\mathrm{Hb}$ was measured using a haemoglobinometer (ACON Mission Plus Hb, ACON Laboratories, Inc., USA). Briefly, about $10 \mu \mathrm{l}$ of capillary blood from a finger prick was placed on the sample pad on the test strip in the haemoglobinometer using a capillary tube and the haemoglobin concentration $(\mathrm{Hb})$ was read within 20 s. The haemoglobinometer was recalibrated 
on a daily bases using the control strip supplied by the manufacturer. In this study, anaemia was defined according to the WHO definition of $\mathrm{Hb}$ level lower than $12.0 \mathrm{~g} / \mathrm{dl}$ for females and $13.0 \mathrm{~g} / \mathrm{dl}$ for males [4]. The severity of anaemia was classified based on the WHO scheme as mild ( $\mathrm{Hb} \geq 11$ but less than normal), moderate $(\mathrm{Hb}$ between 8 and $10.9 \mathrm{~g} / \mathrm{dl}$ ) and severe $(\mathrm{Hb}<8)[17]$.

\section{Blood group determination}

The ABO and Rhesus (D) blood groups were determined using a commercially available kit for blood grouping (HUMAN DIAGNOSTIC, Germany). In determining $\mathrm{ABO}$ and Rhesus blood group, 4 spots of $30 \mu \mathrm{l}$ of washed red cells were placed on a clean plate and anti$\mathrm{A}$, anti-B, anti- $\mathrm{AB}$ and anti-D grouping sera were added, mixed and rocked for 2 mins on a mixer. Positive results were shown by haemagglutination.

Reverse $\mathrm{ABO}$ blood grouping was performed to confirm the blood groups of the participants by determining the reaction of the participants' serum to known $\mathrm{ABO}$ washed red cells.

\section{Statistical analysis}

Statistical analysis was performed using Stata $^{\circ}$ version 12.1 (StataCorp LP) statistical package. Statistical tests performed included univariate and multivariable logistic regression analyses adjusting for gender and age as categorical variable and the Pearson's chi-square for qualitative variables, the student $\mathrm{T}$ test, ANOVA, and Pearson's correlation analysis for quantitative variables. All quantitative variables were normally distributed. Statistical significance was set at $p<0.05$.

\section{Results}

By the end of the study, 1896 potential blood donors were enrolled. Among them were 1,732 (91.35\%) males and $164(8.65 \%)$ females. The participants were between 17 and 52 years of age (mean $\pm \mathrm{SD}=32 \pm 7.81$ ). The donors had donated blood on the average $5.07 \pm 3.54$ times (range: 1-19) in their lifetime.

Five hundred and ninety six (596) of the 1896 donors were anaemic giving a prevalence of $31.44 \%$ (95\% CI: 29.35-33.58). The prevalence of anaemia was higher in females 87/164 (53.1\%) compared to males 509/1732 (29.4\%). A significant association was observed between anaemia and gender $\left(x^{2}=38.91, p \leq 0.0001\right)$. Overall, the prevalence of anaemia was highest in participants of age 20 years and below (62.5\%), and lowest in participants between 30 and 39 years of age (28.6\%) (See Table 1). A significant association was observed between prevalence of anaemia and age $\left(x^{2}=17.32, p=0.001\right)$ (See Table 1$)$. The association between prevalence of anaemia and age
Table 1 Prevalence of anaemia stratified according to age

\begin{tabular}{|c|c|c|c|c|c|c|}
\hline \multirow{2}{*}{$\begin{array}{l}\text { Age } \\
\text { category }\end{array}$} & \multicolumn{2}{|c|}{ Males } & \multicolumn{2}{|c|}{ Females } & \multicolumn{2}{|l|}{ Total } \\
\hline & $\mathrm{N}$ & Anaemic (\%) & $\mathrm{N}$ & Anaemic (\%) & $\mathrm{N}$ & Anaemic (\%) \\
\hline$\leq 20$ & 25 & $15(60.0)$ & 7 & $5(71.4)$ & 32 & $20(62.5)$ \\
\hline $21-2$ & 702 & $200(28.5)$ & 93 & $51(54.8)$ & 795 & 251 (31.6) \\
\hline $30-39$ & 611 & $165(27.0)$ & 39 & $21(53.9)$ & 650 & $186(28.6)$ \\
\hline$\geq 40$ & 394 & $129(32.7)$ & 25 & $10(4$ & 419 & 139 (33.2) \\
\hline Total & 1732 & 509 (29.4) & 164 & $87(53.1)$ & 1896 & 596 (31.4) \\
\hline
\end{tabular}

was significant among males $\left(\chi^{2}=15.369, p=0.002\right)$ but not among females $\left(x^{2}=2.788,0.424\right)$ (See Table 1).

Overall, the prevalence of anaemia was highest in the month of February (39.7\%) and lowest in October (25.2\%) (See Table 2). A marginal association was observed between the prevalence of anaemia and month $\left(X^{2}=19.62, p=0.051\right)$. Among females, the prevalence was highest in March (66.7\%) and lowest in July (33.3\%), while among males, the prevalence was highest in February (39.5\%) and lowest in October (20\%) (See Table 2).

The prevalence of anaemia in the Rainy season was $32.3 \%(318 / 986)$ and in the Dry season, it was 30.6\% (278/910). No significant association was observed in the prevalence of anaemia with season $\left(\chi^{2}=0.64, p=0.425\right)$.

The risk of becoming anaemic was higher in females compared to males [OR $=2.7$ (95\% CI: $1.96-3.75), p \leq$ 0.0001]. Univariate analysis (with January as the reference month) revealed that the risk of becoming anaemic was higher in the month of February $(\mathrm{OR}=1.75, p=$ $0.038)$ and December (OR $=1.73, p=0.036)$ (see Table 2). Furthermore univariate analysis (with February as the reference month) revealed that the risk of becoming anaemic was lower in the months of January $(\mathrm{OR}=0.57$, $p=0.038)$, March $(\mathrm{OR}=0.55, p=0.029)$ and October $(\mathrm{OR}=0.48, p=0.003)$. However multivariate analysis adjusting for age and gender revealed that the risk of becoming anaemic was comparable across the different months of the year (see Table 2).

In all, $457(76.7 \%)$ of the participants had mild anaemia, 129 (21.6\%) had moderate anaemia and 10 (1.7\%) had severe anaemia (see Table 3). No significant association was observed between the degree of anaemia and month $\left(\chi^{2}=27.26 p=0.202\right)$ or season $\left(\chi^{2}=2.23 p=\right.$ $0.328)$.

Overall, the mean $\mathrm{Hb}$ in the study population was $13.42 \pm 1.65$ (range: $6.9-18.9$ ). The mean $\mathrm{Hb}$ in females was $11.78 \mathrm{~g} / \mathrm{dl} \pm 1.44$ (range: $6.9-15$ ), while it was 13.57 \pm 1.59 (range: $7.2-18.9$ ) in males. The mean $\mathrm{Hb}$ was highest in the month of October and lowest in December (see Fig. 1). In males the mean $\mathrm{Hb}$ was highest in October, meanwhile in females, it was highest in May. In males, the mean $\mathrm{Hb}$ was lowest in February while in females, it was lowest in December (see Fig. 1). Multivariate analysis adjusting for gender and age 
Table 2 Prevalence of anaemia stratified according to month and gender in the study population

\begin{tabular}{|c|c|c|c|c|c|c|c|c|}
\hline \multirow[t]{2}{*}{ Month } & \multicolumn{2}{|l|}{ Males } & \multicolumn{2}{|c|}{ Females } & \multicolumn{2}{|l|}{ Total } & \multirow{2}{*}{$\begin{array}{l}\text { Univariate analysis } \\
\text { OR (95\% Cl) }\end{array}$} & \multirow{2}{*}{$\begin{array}{l}\text { Multivariate analysis } \\
\text { OR }(95 \% \mathrm{Cl})\end{array}$} \\
\hline & $\bar{N}$ & $\overline{\text { Anaemic (\%) }}$ & $\overline{\mathrm{N}}$ & Anaemic (\%) & $\bar{N}$ & Anaemic (\%) & & \\
\hline Jan & 120 & $32(26.7)$ & 8 & $3(37.5)$ & 128 & $35(27.3)$ & 1.00 & $0.91(0.55-1.51), p=0.716$ \\
\hline Feb & 124 & $49(39.5)$ & 12 & $5(41.7)$ & 136 & $54(39.7)$ & $1.75(1.04-2.94), p=0.038$ & $1.54(0.96-2.47), p=0.077$ \\
\hline Mar & 133 & $33(24.8)$ & 6 & $4(66.7)$ & 139 & $37(26.6)$ & $0.96(0.56-1.66), p=0.894$ & $0.90(0.55-1.48), p=0.677$ \\
\hline Apr & 172 & $46(26.7)$ & 20 & $10(50.0)$ & 192 & $56(29.2)$ & $1.04(0.67-1.8), p=0.723$ & $0.92(0.59-1.45), p=0.729$ \\
\hline May & 161 & 53(32.9) & 12 & $3(25.0)$ & 173 & $56(32.4)$ & $1.16(0.7-1.9), p=0.548$ & $1.13(0.72-1.79), p=0.591$ \\
\hline Jun & 113 & $36(31.9)$ & 10 & $5(50.0)$ & 123 & $41(33.3)$ & $1.33(0.77-2.28), p=0.302$ & $1.16(0.71-1.91), p=0.555$ \\
\hline Jul & 111 & $32(28.8)$ & 6 & $2(33.3)$ & 117 & $34(29.1)$ & $1.09(0.62-1.9), P=0.765$ & $1.01(0.6-1.69) \cdot p=0.973$ \\
\hline Aug & 119 & $31(26.1)$ & 9 & $5(55.6)$ & 128 & $36(28.1)$ & $1.04(0.6-1.8), p=0.889$ & $0.91(0.55-1.50), p=0.700$ \\
\hline Sep & 155 & $43(27.7)$ & 22 & $12(54.6)$ & 177 & $55(31.1)$ & $1.2(0.73-1.98), p=0.48$ & 1.00 \\
\hline Oct & 160 & $32(20.0)$ & 20 & $11(55.0)$ & 180 & $43(25.2)$ & $0.83(0.5-1.4), p=0.492$ & $0.71(0.44-1.14), p=0.154$ \\
\hline Nov & 233 & 73(31.3) & 28 & $20(71.4)$ & 261 & $93(35.6)$ & $1.47(0.93-2.34), p=0.102$ & $1.29(0.85-1.96), p=0.226$ \\
\hline Dec & 131 & 49(37.4) & 11 & $7(63.6)$ & 142 & $56(39.4)$ & $1.73(1.04-2.89), p=0.036$ & $1.54(0.96-2.47), p=0.071$ \\
\hline Total & 1732 & $509(29.39)$ & 164 & $87(53.05)$ & 1896 & $596(31.44)$ & & \\
\hline
\end{tabular}

revealed no significant association between mean $\mathrm{Hb}$ and month $(p=0.079)$.

In this study, no significant difference was observed in the mean $\mathrm{Hb}$ between the rainy and the dry season ( $p=$ 0.350) adjusting for age and gender (see Fig. 2).

In the current study, no significant correlation was observed between $\mathrm{Hb}$ and age $(r=0.043, p=0.062)$.

The prevalence of anaemia was highest in participants with blood group AB 16(64\%) (see Table 4). A significant association was observed between anaemia and blood group $\left(\chi^{2}=15.63, p=0.001\right)$.

In all, 1827 (96.4\%) of the participants were Rhesus (D) positive while 69 (3.6\%) were Rhesus (D) negative.

Table 3 Severity of anaemia with respect to month in the study population

\begin{tabular}{lllll}
\hline Month & \multicolumn{2}{l}{ Degree of anaemia } & Total \\
\cline { 2 - 4 } & Mild (\%) & Moderate (\%) & Severe (\%) & \\
\hline Jan & $30(85.7)$ & $5(14.3)$ & $0(0)$ & 35 \\
Feb & $45(83.3)$ & $9(16.7)$ & $0(0)$ & 54 \\
Mar & $30(81.1)$ & $6(16.2)$ & $1(2.7)$ & 37 \\
Apr & $44(78.6)$ & $12(21.4)$ & $0(0)$ & 56 \\
May & $50(89.3)$ & $6(10.7)$ & $0(0)$ & 56 \\
Jun & $31(75.6)$ & $10(24.4)$ & $0(0)$ & 41 \\
Jul & $29(85.3)$ & $5(14.7)$ & $0(0)$ & 34 \\
Aug & $23(63.9)$ & $12(33.3)$ & $1(2.8)$ & 36 \\
Sep & $39(70.9)$ & $15(27.3)$ & $1(1.8)$ & 55 \\
Oct & $34(79)$ & $7(16.3)$ & $2(4.7)$ & 43 \\
Nov & $63(67.7)$ & $27(29)$ & $3(3.2)$ & 93 \\
Dec & $39(69.6)$ & $15(26.8)$ & $2(3.6)$ & 56 \\
Total & $457(76.7)$ & $129(21.6)$ & $10(1.7)$ & 596 \\
\hline
\end{tabular}

The prevalence of anaemia was higher among participants that were Rhesus (D) positive 575 (31.5\%) compared to those that were Rhesus (D) negative 21 (30.4\%). However no significant difference was observed between prevalence of anaemia and the Rhesus (D) antigen $\left(x^{2}=\right.$ 0.033, $p=0.855)$.

\section{Discussion}

Anaemia is one of the main factors of clinical deferral of blood donors in developing countries including Cameroon. In this study, we investigated the prevalence of anaemia and its association with blood phenotypes as well as month among blood donors in Fako division of Cameroon. A high prevalence of $31.44 \%$ was observed in this study. The prevalence was higher compared to the $16 \%$ reported in Nigeria [18], 4.2\% in Brazil [13], and $1.8 \%$ in India [19]. The difference between the prevalence of anaemia in these studies compared to ours could be attributed to the differences in the nutritional habits of these populations. Malnutrition and infectious diseases (such as malaria, intestinal parasitic infections, HIV) are some of the main factors contributing to the high prevalence of anaemia especially in children in Cameroon [12]. The high prevalence of anaemia implies $31.44 \%$ of the donors were deferred as a result of the anaemia over the year thereby constituting a huge loss of blood stock. Low supply of blood in a country with a high prevalence of anaemia like Cameroon will compromise the blood supply and therefore have an adverse effect on the quality of health care. In this study, the prevalence of anaemia was significantly higher in females compared to males, which is in line with studies performed elsewhere [19, 20]. Females were also observed to be at increased risk of anaemia in comparison to their 

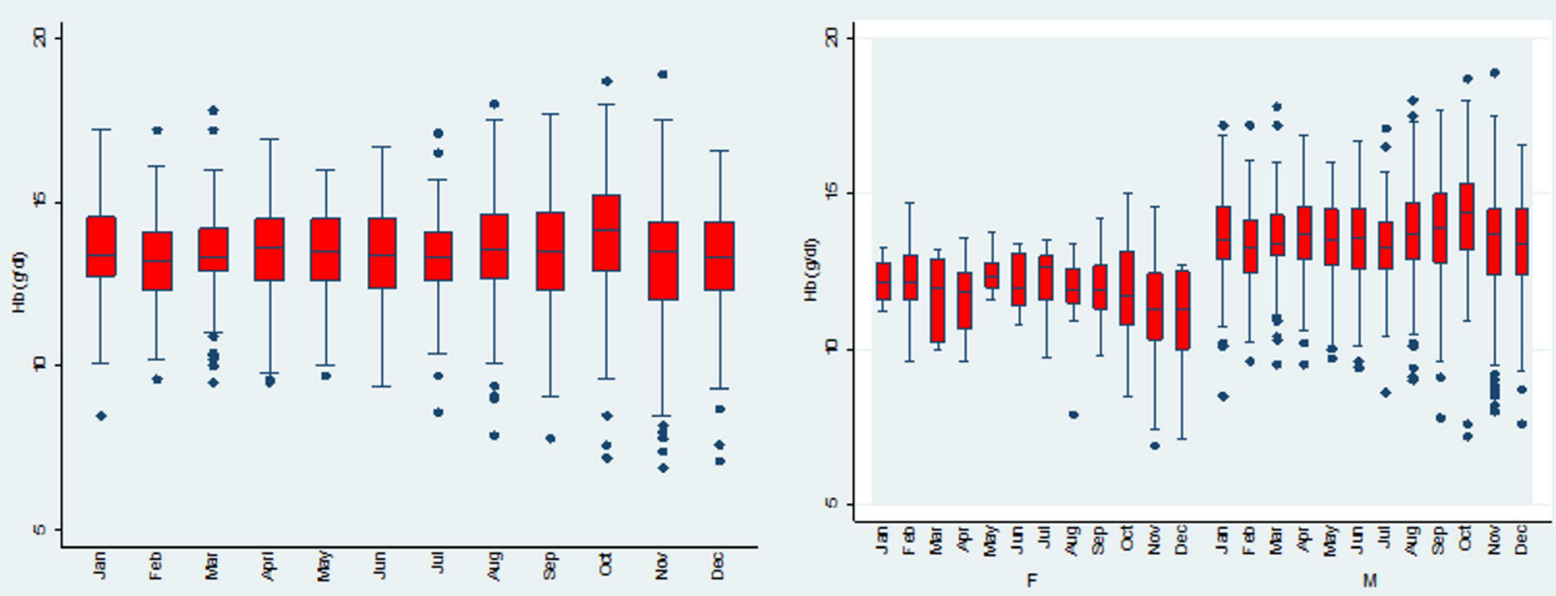

Fig. 1 Monthly distribution of $\mathrm{Hb}$ in the study population overall (left), and stratified according to gender (right). No significant association was observed between $\mathrm{Hb}$ and month adjusting for age and gender

male counterparts (OR $=2.7, p \leq 0.0001)$. This is not unusual owing to the fact that women often fail to compensate their menstruational blood loss. In this study, $8.65 \%$ of the donors were females. Pregnancy, lactation and menstruation are some of the causes preventing blood donation in females. This may have resulted in a selection bias against females consequently influencing the true representation of the prevalence of anaemia in this group. The finding of fewer female donors in this study corroborate with work done by Silva et al. [13]. In this study, the prevalence of anaemia was observed to be higher in participants of 20 years and below irrespective of gender. A significant association was observed between prevalence of anaemia and age $(p=0.001)$. The finding of higher prevalence of anaemia among younger donors could be attributed to the fact that many of them were students who undergo a lot of stress with their study and hardly feed well. The association between prevalence of anaemia and age was significant among males but not among females. This difference could be
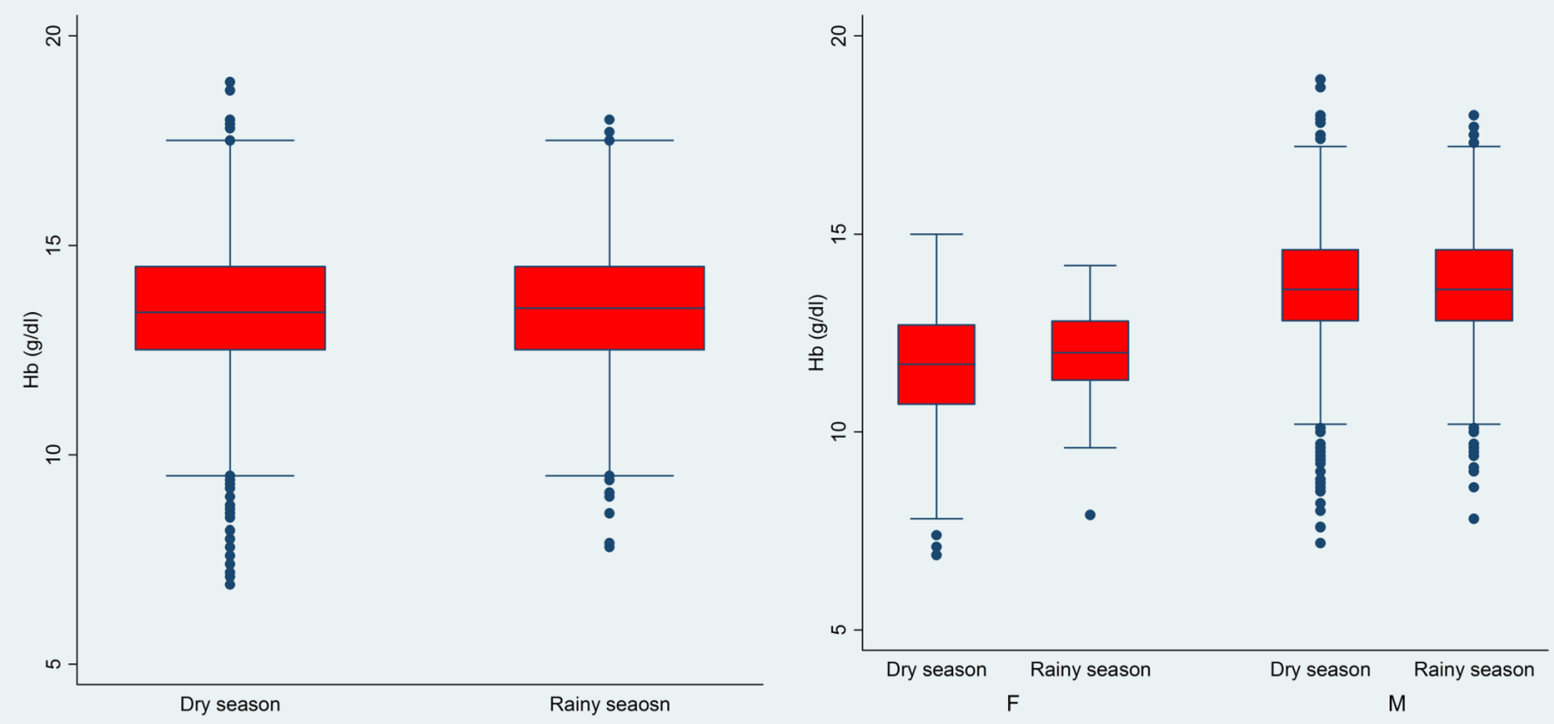

Fig. 2 Distribution of mean $\mathrm{Hb}$ according to season in the study population. The mean $\mathrm{Hb}$ was observed to be higher in the rainy season overall (left) and in both males and females (right). The difference in the mean Hb between the two seasons was not observed to be significant $(p=0.350)$ adjusting for age and gender 
Table 4 The distribution of anaemia with respect to blood phenotype

\begin{tabular}{lllll}
\hline Blood group & N & Anaemic (\%) & $X^{2}$ & $P$-value \\
\hline A & 231 & $73(31.6)$ & 15.63 & 0.001 \\
AB & 25 & $16(64)$ & & \\
B & 216 & $78(36.1)$ & & \\
O & 1424 & $429(30.1)$ & & \\
Total & 1896 & 596 & & \\
\hline
\end{tabular}

due to the observation that the prevalence of anaemia was generally high among females irrespective of the age.

In this study, it was observed that the donors had donated blood on the average of 5 times in their lifetime. Studies have shown that there is an increasing depletion of the iron stores with increasing number of blood donation [21-23]. The high frequency of blood donation observed in this study could have also contributed to the high prevalence of anaemia observed in this study.

We also observed the prevalence of anaemia to be highest in February and lowest in October. In the study area, the dry season is usually between October and March meanwhile the rainy season is between April and September. February which has the highest rate of anaemia falls in the heart of the dry season during which there is scarcity of foodstuffs including vegetables, which are also very expensive where available. This negatively affects the feeding habit of the population of Fako hence the high rate of anaemia. October which has the lowest prevalence of anaemia falls in the transition between the dry and the rainy season. During this period there is abundance of foodstuffs especially vegetables, which are also cheaper. At this time of the year, vegetables constitute a large part of the diet hence the lower prevalence of anaemia. A marginal association was observed between prevalence of anaemia and months in this study. The prevalence of anaemia was higher in the dry season compared to the rainy season which is not unusual. However no significant association was observed between prevalence of anaemia and season. The risk of developing anaemia was also observed to be higher in February and December but multivariate analysis adjusting for age and gender revealed similar risk of anaemia across the different months of the year. Like the prevalence of anaemia, no significant association was observed between the degree of anaemia and month.

The mean $\mathrm{Hb}$ observed in this study was $13.42 \mathrm{~g} / \mathrm{dl}$ and ranged between 6.9 and $18.9 \mathrm{~g} / \mathrm{dl}$. The mean $\mathrm{Hb}$ was lower in females $(11.78 \mathrm{~g} / \mathrm{dl})$ compared to males $(13.57 \mathrm{~g} / \mathrm{dl})$. This is not unusual owing to the fact that the $\mathrm{Hb}$ of females is generally always lower than the $\mathrm{Hb}$ in males for reasons highlighted above. The mean $\mathrm{Hb}$ was highest in October and lowest in December. In this study, no significant association was observed between $\mathrm{Hb}$ and month $(p=0.079)$ adjusting for age and gender. The variation in the mean $\mathrm{Hb}$ with month could be attributed to the same factors associated with the prevalence of anaemia highlighted above. In females, the mean $\mathrm{Hb}$ was highest in the month of May and lowest in December, which is contrary to males in which mean $\mathrm{Hb}$ was observed to be highest in October and lowest in February. Like with the prevalence of anaemia in this study, no significant association was observed between $\mathrm{Hb}$ and season $(p=0.350)$, neither was there any significant association between $\mathrm{Hb}$ and age $(p=0.062)$.

In this study, it was observed that anaemia was significantly associated with blood group $\mathrm{AB}(p=0.001)$. Not many studies have associated a particular blood group with anaemia in the literature. A previous study in 1956 had linked pernicious anaemia to blood group A [24]. In this study we did not determine the aetiology of anaemia which prevented us from knowing the exact type of anaemia associated with blood group AB. The prevalence of anaemia was higher in donors who were Rhesus (D) positive (31.5\%) compared to Rhesus (D) negative (30.4\%) donors. However this difference was not observed to be significant $(p=0.855)$. This difference could be attributed to the fact that the majority of donors were Rhesus (D) positive (96.4\%).

In the current study, we did not determine the aetiology and risk factors for anaemia in the study population and this constitutes a major limitation. Studies are therefore required to ascertain the aetiology of anaemia in the study population as well as make prepositions to reduce the high rate of anaemia in blood donors in the study area.

\section{Conclusion}

A high prevalence of anaemia (31.44\%) was observed which translates to an equivalent number of blood donors deferred as a result of anaemia in the study timeframe. The prevalence of anaemia was significantly higher in females compared to males and in participants of age 20 years and below. A marginal association was observed between the prevalence of anaemia and month but not with the season. The risk of developing anaemia was comparable across the different months of the year. Female blood donors and donors with the blood group $\mathrm{AB}$ were the most at-risk of developing anaemia compared to the others. In the current study, no association was observed between the mean $\mathrm{Hb}$ and month neither was there any association between mean $\mathrm{Hb}$ and season.

Further studies will therefore be required to ascertain the aetiology and risk factors for anaemia in the study population as well as make prepositions aimed at reversing the current high rate of anaemia in the study population. 


\section{Abbreviations}

$\mathrm{Cl}$ : Confidence interval; Hb: Haemoglobin concentration; OR: Odd ratio

\section{Acknowledgements}

The authors wish to thank the director, doctors, nurses and laboratory staff of the Regional Hospital of Buea for allowing us to use their donors and for their help in the data collection. Our sincere gratitude also goes to the blood donors who took part in this study.

\section{Funding}

This study was funded by the authors.

\section{Availability of data and materials}

All the data supporting this findings have been presented in the manuscript.

\section{Authors' contributions}

TEK conceived and designed the study, participated in data collection, took part in the analysis and interpretation, conducted the literature search and review and critically revised the paper. TDBK participated in the statistical analysis, conducted the literature search and review and wrote the first draft of the paper. All authors read and approved the final paper.

\section{Competing interest}

The authors declare that they have no competing interest.

\section{Consent for publication}

Not applicable.

\section{Ethics approval and consent to participate}

The study protocol was approved by the Faculty of Health Sciences Institutional Review Board (IRB) of the University of Buea, Cameroon. Administrative clearance was obtained from the Regional Delegation of Public Health of the South West Region of Cameroon and from the director of the Regional Hospital of Buea. Written informed consent was obtained from all participants prior to their inclusion.

\section{Author details}

${ }^{1}$ Regional Hospital Buea, P.O. Box 32, Buea, South West Region, Cameroon. ${ }^{2}$ Department of Medical laboratory Sciences, Faculty of Health Sciences, University of Buea, P.O. Box 63, Buea, Cameroon. ${ }^{3}$ Department of Microbiology and Parasitology, Faculty of Science, University of Buea, P.O. Box 63, Buea, Cameroon.

Received: 29 October 2015 Accepted: 22 November 2016 Published online: 28 November 2016

\section{References}

1. WHO. Iron Deficiency Anemia: assessment, prevention and control. Geneva: WHO; 2001. http://apps.who.int/iris/bitstream/10665/66914/1/WHO_NHD_ 01.3.pdf?ua=1. Accessed 22 Oct 2015

2. Kumar V, Abbas AK, Fausto N, Mitchell R. Robbin's basic pathology. 8th ed. Philadelphia: Saunders; 2007. ISBN 1-4160-2973-7.

3. Janz TG, Johnson RL, Rubenstein SD. Anemia in the emergency department: evaluation and treatment. Emerg Med Pract. 2013;15 Suppl 11:1-15. quiz $15-6$.

4. WHO. Worldwide prevalence of anaemia 1993 - 2005: WHO global database on anaemia. Geneva: World Health Organisation; 2008. http:// whqlibdoc.who.int/publications/2008/9789241596657_eng.pdf. Accessed 22 Oct 2015

5. Anorlu Rl, Odum CU, Essien EE. Asymptomatic malaria parasitaemia in pregnant women at booking in a primary health care facility in a periurban community in Lagos, Nigeria. Afr J Med Sci. 2001;30:39-41.

6. Aimakhu CO, Olayemi O. Maternal haematocrit and pregnancy outcome in Nigerian women. West Afr J Med. 2003;22:18-21.

7. Sandstead $\mathrm{HH}$. Causes of iron and zinc deficiencies and their effects on brain. J Nutr. 2000:130:347S-9S.

8. Stevens GA, Finucane MM, De-Regil LM, Paciorek CJ, Flaxman SR, Branca F et al. Global, regional, and national trends in haemoglobin concentration and prevalence of total and severe anaemia in children and pregnant and non-pregnant women for 1995-2011: a systematic analysis of populationrepresentative data. Lancet Glob Health. 2013;1 Suppl 1:e16-25.
9. Korenromp EL, Armstrong-Schellenberg JR, Williams BG, Nahlen BL, Snow RW. Impact of malaria control on childhood anaemia in Africa - a quantitative review. Trop Med Int Health. 2004;9:1050-65.

10. Richardson DJ, Richardson KR, Richardson KE, Gross J, Tsekeng P, Dondji B, Foulefack S. Malaria, intestinal parasitic infection, anemia, and malnourishment in Rural Cameroonian Villages with an assessment of early interventions. J Ark Acad Sci. 2011;65:72-97.

11. Zeukeng F, Tchinda VHM, Bigoga JD, Seumen CHT, Ndzi ES, Abonweh G, et al. Co-infections of malaria and geohelminthiasis in two Rural Communities of Nkassomo and Vian in the Mfou Health District, Cameroon. PLoS Negl Trop Dis. 2014;8 Suppl 10:e3236.

12. Njunda AL, Fon SG, Assob JCN, Nsagha DS, Kwenti TZB, Kwenti ET. Coinfection with malaria and intestinal parasites, and its association with anaemia in children in Cameroon. Infect Dis Poverty. 2015;4:43.

13. Silva MA, de Souza RA, Carlos AM, Soares S, Moraes-Souza H, Pereira GA Etiology of anemia of blood donor candidates deferred by hematologic screening. Rev Bras Hematol Hemoter. 2012;34 Suppl 5:356-60.

14. Bondevik GT, Lie RT, Ulstein M, Kvale G. Seasonal variation in the risk of anaemia among pregnant Nepali women. Int J Gynaecol Obstet. 2000;69(3): 215-22.

15. Palva IP, Salokannel SJ. Seasonal variation in megaloblastic anaemia. Br J Nutr. 1972:27:593-5.

16. Statoids. Annuaire Statistique du Cameroun 2006. Obtained from Institut National de la Statistique du Cameroun. http://www.statoids.com/ycm.html. 2009. Accessed 25 Oct 2015

17. WHO. Haemoglobin concentrations for the diagnosis of anaemia and assessment of severity. Geneva: WHO; 2011. http://www.who.int/vmnis/ indicators/haemoglobin.pdf. Accessed 22 Oct 2015.

18. Erhabor O, Imrana S, Buhari H, Abubakar W, Abdulrahaman Y, Isaac IZ, et al. Prevalence of anaemia among Blood Donors in Sokoto, North Western, Nigeria. Int J Clin Med Res. 2014;1 Suppl 3:85-9.

19. Bahadur S, Pujani M, Jain M. Donor deferral due to anemia: A tertiary care center-based study. Asian J Transfusion Sci. 2011:5:53-5.

20. Gupta AK, Agarwal SS, Kaushak R, Jain A, Gupta VK, Khare N. Prevalence of anemia among rural population living in and around of rural health and training center, Ratua village of Madhya Pradesh. Muller J med Sci Res. 2014;5:15-8.

21. Badar A, Ahmed A, Ayub M, Ansari AK. Effect of frequent blood donations on iron stores of non anaemic male blood donors. J Ayub Med Coll Abbottabad. 2002;14 Suppl 2:24-7.

22. Cançado RD, Chiattone CS, Alonso FF, Langhi Júnior DM, Alves Rde C. Iron deficiency in blood donors. Sao Paulo Med J. 2011;119 Suppl 4:132-4.

23. Addullah SM. The effect of repeated blood donations on the iron status of male Saudi blood donors. Blood Transf. 2011:9:167-71.

24. Aird I, Bentall HH, Bingham J, Blackburn EK, Mackay MS, Swan HT et al. An association between blood group $\mathrm{A}$ and pernicious anaemia: a collective series from a number of centres. BMJ 1956;2:723-724.

\section{Submit your next manuscript to BioMed Central and we will help you at every step:}

- We accept pre-submission inquiries

- Our selector tool helps you to find the most relevant journal

- We provide round the clock customer support

- Convenient online submission

- Thorough peer review

- Inclusion in PubMed and all major indexing services

- Maximum visibility for your research

Submit your manuscript at www.biomedcentral.com/submit
Biomed Central 